\title{
Evaluation of Genotype Diversity in Oat Germplasm and Definition of Ideotypes Adapted to the Mediterranean Environment
}

\author{
Anna Iannucci, Pasquale Codianni, and Luigi Cattivelli \\ CRA-Centro di Ricerca per la Cerealicoltura, S.S. 16 Km 675, 71122 Foggia, Italy
}

Correspondence should be addressed to Anna Iannucci, anna.iannucci@entecra.it

Received 21 March 2011; Revised 17 May 2011; Accepted 2 June 2011

Academic Editor: David Clay

Copyright ( $) 2011$ Anna Iannucci et al. This is an open access article distributed under the Creative Commons Attribution License, which permits unrestricted use, distribution, and reproduction in any medium, provided the original work is properly cited.

\begin{abstract}
Oat (Avena sativa L.) is a cereal species widely used for human food and livestock feed. It is rich in primary metabolites (e.g., protein, carbohydrate, and fibre) as well as in many secondary compounds (e.g., fructo-oligosaccharides). A germplasm evaluation was carried out to determine the genetic diversity, using univariate and multivariate analyses, and to define an oat ideotype for grain and fodder production adapted to the Mediterranean environment. A total of 109 genotypes were studied under field conditions in Foggia (southern Italy) over two growing seasons (2008-2009 and 2009-2010). All of the accessions were characterised according to 13 bioagronomic traits. Accessions were very different for these evaluated traits, with wide variabilities found particularly for seed yield and fructo-oligosaccharide concentration $(\mathrm{CV}=37 \%)$. Principal component analysis showed that the first six axes accounted for $81 \%$ of the variability. Productivity characteristics and heading time were the major sources of diversity among these oat populations. Clustering entries identified nine groups based on their morphological and agronomic properties. The relationships found among traits can help to determine which groups of genotypes are better adapted to specific environmental conditions and to identify ideotypes for developing varieties for different purposes such as for food or forage.
\end{abstract}

\section{Introduction}

Oat (Avena sativa L.) is used throughout the world for human food and animal feed, and it is frequently grown as a dual-purpose crop (grain harvest after grazing or forage cutting) [1]. As a pure stand, or also associated with the most common annual legumes, oat is one of the major forages grown and a main component of crop rotation in Mediterranean farming systems [2]. In recent years, its agronomic and nutritive values, as well as the increase in the popularity of organic agriculture due to its ability as a winter cover crop in no-till rotations, have led to renewed interest in this crop. Furthermore, the demand for oat for human consumption has increased, particularly because of the demonstrated dietary benefits of oat whole-grain products [3]. Oat is considered to be a nutritious source of protein, carbohydrate, fibre, vitamins, and minerals as well as of compounds with beneficial effects on health (e.g., polymers of fructose, and antioxidant molecules) [4]. In particular, oat grain has a high concentration of fructo-oligosaccharides (FOS), soluble nonstructural carbohydrates made of short chains of fructose molecules [5]. FOS have been termed "prebiotics", because they can selectively stimulate growth and/or activity of a number of potentially health-stimulating intestinal bacteria, and they have essential roles in many molecular processes that impact upon eukaryotic biology and disease [6]. Recently, a new approach in the feed supply chain has suggested that milk production and composition can be influenced by the availability and characteristics of the soluble carbohydrates in the animal diet [7]. However, little is known about the variability of FOS concentrations in the forage biomass of cereals.

At present, the same varieties of oat that are usually used for fodder are also used for grain. Oat genotypes have generally been selected for high grain yield and harvest index, pest resistance, and/or environmental stress tolerance [8]. However, fodder cultivars must produce large amounts of highly digestible green fodder for animals, must have high 
regrowth ability following cutting, and must be resistant to potential plant diseases that can limit fodder yield in the production areas [9]. Within this context, an oat ideotype that can be reliably cultivated in the Mediterranean areas for grain or fodder crop is needed.

The first step in a breeding programme is to determine the amount of variation that is present in the characters of agronomic importance within a large collection of materials in order to define the valuable populations to be considered further. Assessment of the genetic variability can be achieved using morphological measurements and phenotypic characterisation [10]. Bioagronomic characterisation carried out using appropriate statistical methods continues to be a useful tool for the initial description and classification of oat collections, as it allows plant breeders to identify and select valuable genetic resources for direct use by farmers, in breeding programmes, or for planning efficient germplasm conservation and use $[11,12]$. The genetic variation in the germplasm for the agronomic traits can be subjected to multivariate analysis (principal component analysis (PCA) and cluster analysis) to establish the relationships among various accessions.

The objectives of this study were to: (i) explore and quantify the genetic variation of the main bioagronomic traits, (ii) analyse the degree of similarity/dissimilarity among 109 oat accessions using a multivariate statistical approach, and (iii) define the oat ideotypes for grain or fodder production that are applicable for plant breeding under Mediterranean conditions.

\section{Materials and Methods}

The experiments were carried out during the 2008-2009 and 2009-2010 cropping seasons at the Cereal Research Centre in Foggia (Italy) $\left(41^{\circ} 28^{\prime} \mathrm{N}, 15^{\circ} 34^{\prime} \mathrm{E}, 76 \mathrm{~m}\right.$ a.s.l.). The trials were performed in loam soil (USDA classification) with the following characteristics: $21 \%$ clay, $43 \%$ silt, $36 \%$ sand, pH 8 (in $\mathrm{H}_{2} \mathrm{O}$ ), $15 \mathrm{mg} \mathrm{kg}^{-1}$ available $\mathrm{P}$ (Olsen method), $800 \mathrm{mg} \mathrm{kg}^{-1}$ exchangeable $\mathrm{K}\left(\mathrm{NH}_{4} \mathrm{Ac}\right)$, and $21 \mathrm{~g} \mathrm{~kg}^{-1}$ organic matter (Walkey-Black method). Daily maximum and minimum temperatures, as well rainfall of the two experimental growing seasons were contrasted with historical means (1955-2006). All climatic data were obtained from an on-site weather station. Maximum and minimum daily temperatures were used to calculate growing degree days (GDD) with a $0^{\circ} \mathrm{C}$ baseline temperature.

A total of 109 genotypes from different geographical origins were evaluated that belonged to old and modern cultivars and advanced breeding lines. The experimental design was with a randomised complete block with one replicate being grown in each of two years. The plot size was $10 \mathrm{~m}^{2}$, with 8 rows that were $7.5 \mathrm{~m}$ long and $0.17 \mathrm{~m}$ apart; sowing was during the second half of November, at a seeding density of 350 seeds $\mathrm{m}^{-2}$. A dose of $200 \mathrm{~kg} \mathrm{ha}^{-1}$ of $18 / 46$ fertiliser ( $18 \%$ elemental $\mathrm{N}, 46 \% \mathrm{P}_{2} \mathrm{O}_{5}$, by weight) was applied at sowing. During plant tillering, the plots were top-dressed with $200 \mathrm{~kg} \mathrm{ha}^{-1} \mathrm{NH}_{4} \mathrm{NO}_{3}$ (26\% elemental $\mathrm{N}$ ). For weed control, a herbicide was applied each year at the tillering stage.
During 2009, five plants for each genotype were harvested for FOS determination, when the first two or three spikelets of $50 \%$ of the oat panicles in each plot had emerged from the boot (Feekes's growth stage, 10.1). The plants were cut into small pieces and immediately stored at $-80^{\circ} \mathrm{C}$ until chemical analysis. A subsample of about $100 \mathrm{~g}$ was oven-dried under vacuum at $40^{\circ} \mathrm{C}$ for $48 \mathrm{~h}$, weighed, and then ground through a cyclone mill with a $1-\mathrm{mm}$ screen. Enzymatic methods (Megazyme, methods AOAC 999.03 and AACC 32.32) were used for determination of the FOS content (\% dry weight (d.w.)). For each plot in both years, the following traits were determined: heading time (HT; days from 1 April), maturity time (MT; days from 1 April) and filling period (FP; days), as the differences between maturity and heading time. Physiological maturity was measured as the date when $50 \%$ of the panicles within a plot had reached $80 \%$ chlorophyll loss (Feekes's growth stage, 11.4). Furthermore, at maturity, which was approximately 210 days after sowing, the seed yield (SY; $\mathrm{g} \mathrm{m}^{-2}$ ) was determined after harvesting the six inner rows in a plot. The plant height $(\mathrm{PH}$; $\mathrm{cm}$ ), seed test (ST; $\mathrm{kg} \mathrm{hL}^{-1}$ ), and 1,000 seed weight (TSW; g) were also recorded in both years of evaluation. During 2009, the seed yield components were determined in a linear metre row previously removed from the centre of each plot and stored separately, and 30 random and representative panicles were used to determine traits related to panicles. Agronomic characters recorded were: plant density $\left(\mathrm{NP} / \mathrm{m}^{-2} ;\right.$ no. $\left.\mathrm{m}^{-2}\right)$, panicle density $\left(\mathrm{NPa} / \mathrm{m}^{-2}\right.$; no. $\left.\mathrm{m}^{-2}\right)$, seed weight per panicle (SW/Pa; g), and seeds per panicle (NS/Pa; no.). The Harvest index (HI) was calculated as the ratio between grain yield and biological yield.

2.1. Statistical Analysis. The means, standard errors, coefficients of variation ( $\mathrm{CV} ; \%)$, and range for all of the bioagronomic traits were calculated over the two growing seasons for whole collection. An analysis of variance including the fixed factor genotype and the random factor year was carried out for each trait, using genotype $\times$ year as the error term for genotype main effects. Furthermore, we calculated all of the possible correlation coefficients among the traits recorded during 2009. To investigate the importance of the different traits in the explanation of multivariate polymorphism in oat genotypes, PCA was developed with the aid of the STATISTICA software (StatSoft version 7.1 StatSoft, Inc., Tulsa, Okla, USA). Data for different traits were standardised to a mean of zero and variance of one, to overcome differences in size during recording [13]. Six principal components were extracted by determining the relative scores. Cluster analysis was performed to measure the hierarchical similarity among genotypes. From the PCA values, a Euclidean distance matrix was established [14] to obtain a relative dendrogram. The entries were clustered using Ward's minimum-variance method. The reference line on the dendrogram was drawn where the number of clusters was equal to approximately $20 \%$ of the total distance. First and second principal component axes scores were plotted to aid visualization of accession differences. In addition, the oat populations were arbitrarily grouped for seed yield potential 
as high $(\mathrm{SY} \geq$ mean + standard deviation $(\mathrm{SD}))$, medium (mean $-\mathrm{SD}<\mathrm{SY}>$ mean $+\mathrm{SD})$, or low $(\mathrm{SY} \leq$ mean $\mathrm{SD})$ and for heading time as early (HT $<$ mean time) or late (HT $\geq$ mean time).

\section{Results}

Meteorological conditions for the two growing seasons, with long-term means, from the local weather station in Foggia, are shown in Table 1. Years were very similar in mean maximum and minimum temperatures, in total rainfall, and in GDD values. A maximum difference of $1.3^{\circ} \mathrm{C}$ was recorded from the 52-yr mean, whereas compared with long-term climate data, both growing seasons resulted rainy.

The descriptive statistics (i.e., mean, range, $\mathrm{CV}$ ) for the 13 quantitative traits are reported in Table 2. The most variable traits were seed yield, HI, FOS content, seed weight, and seed number per panicle. The lowest variation was estimated for time to maturity and plant height; all the other traits showed intermediate values. Seed yield ranged from $118 \mathrm{~g} \mathrm{~m}^{-2}$ (cv. Plata) to $606 \mathrm{~g} \mathrm{~m}^{-2}$ (cv. Alcudia), while other important traits also showed large levels of divergence. Indeed, the days to heading ranged from 18 to 45 days. Furthermore, oat is generally a tall plant and the accessions analysed showed a mean height of $133 \mathrm{~cm}$, with breeding line BD 118 as the shortest $(107.5 \mathrm{~cm})$ and breeding line Vir 2301 as the tallest $(162.5 \mathrm{~cm})$. The number of panicles per $\mathrm{m}^{2}$ also had a wide range, varying from 246 to 918 , with a mean of 495 panicles per $\mathrm{m}^{2}$, while the FOS content in the biomass ranged from $1.12 \%$ to $6.70 \%$. Among the traits related to the seeds, the seed test is important for the agronomic quality, and it ranged from $33.9 \mathrm{~kg} \mathrm{hL}^{-1}$ (cv. Pluco) to $53.5 \mathrm{~kg} \mathrm{hL}^{-1}$ (Rhea $\times$ Peniarth). As an important character to indicate seed size, the TSW ranged from $13.7 \mathrm{~g}$ (cv. Roar Se Jet) to $36.5 \mathrm{~g}$ (breeding line PC 59). Furthermore, differences among genotypes were statistically significant for most of the traits recorded in both years.

The correlation matrices showed some significant correlations between the plant characters (Table 3). The heading and maturity times were negatively correlated with the seed yield, HI and TSW. The seed yield increased with increased $\mathrm{HI}, \mathrm{SW} / \mathrm{Pa}$ and TSW. In turn, HI was positively correlated to $\mathrm{NPa} / \mathrm{m}^{2}, \mathrm{NS} / \mathrm{Pa}, \mathrm{SW} / \mathrm{Pa}$, and TSW. No significant correlations were observed between FOS content in the biomass and the other traits.

To determine the patterns of variation and to detect the structure in the relationships between traits, PCA was carried out considering all of the 13 variables simultaneously (Table 4). The eigenvalues representing the variance of the principal components, the cumulative percentages of the eigenvalues that indicate the percentage contributions to the total variance attributable to each principal component, and the eigenvectors indicating the degree of association among the original data and each principal component are also reported in Table 4. The first six principal components (PC1PC6) accounted for more than $81 \%$ of the total variation estimated, with $\mathrm{PC} 1$ comprising $23.4 \%$ of total variation estimated, PC2 17.5\%, PC3 14.5\%, PC4 9.3\%, PC5 8.9\%, and PC6 7.5\%. The characteristics of each principal component

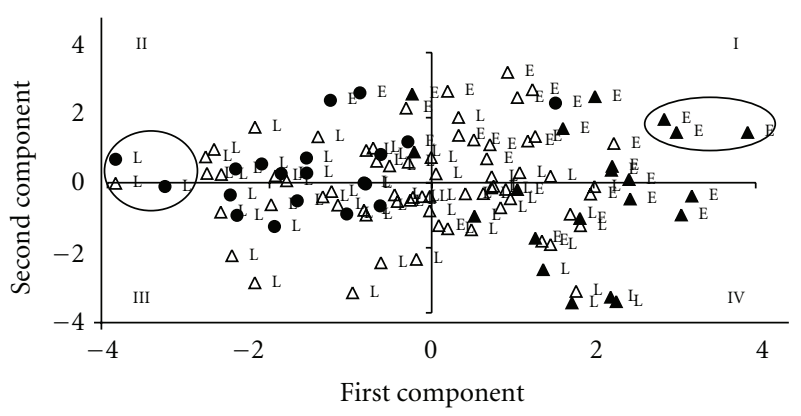

Figure 1: Score plot of the first two principal components of the 109 genotypes of oat: seed yield group (high $(\Delta)$, medium $(\triangle)$, and low $(\bullet))$ and heading time group (early (E) and late (L)).

were determined on the basis of estimated factor loadings. PC1 was related to SY, HI, SW/Pa and TSW; PC2 to HT, MT, filling period (FP), and $\mathrm{NPa} / \mathrm{m}^{2}$; $\mathrm{PC} 3$ to $\mathrm{SW} / \mathrm{Pa}$, and $\mathrm{NS} / \mathrm{Pa}$; PC4 to FOS content and $\mathrm{NPa} / \mathrm{m}^{2}$; PC5 to $\mathrm{PH}$ and ST; and PC6 to FOS content. Considering the loadings relative to the first and second components, it can be inferred that productivity characters, that is SY, HI, and TSW, (with positive eigenvectors) together with heading time (with a negative eigenvector) are the major sources of diversity among these oat populations.

Due to low values in factor loadings, the scatter diagram of the first two principal components shows no evident and significant groups of genotypes (Figure 1) However, the phenotypic variation among these accessions of oat for seed yield and heading time was large, and the dispersion along both of the principal component axes supported delimitation of the genotypes based on observations of these two traits. Accessions with high yield potential were on the right side of the scatter plots, and a distinct phenological gradient was formed from late to early. Each group of heading time had a distinct position, although some overlap occurred. The three accessions with the highest positive and negative coefficients of the first component (first and second quadrant, resp.) were both cultivars and breeding lines.

These most divergent accessions, according to variation, along with the first two principal components are given in Table 5. It is interesting to note that populations with the same high seed yield potential differed by more than 2 weeks in the heading times. In particular, Genziana showed higher HI, whereas the breeding line CW 0002/58 was shorter and earlier, with a long FP, lower HI, and high FOS content. Furthermore, these differed for other important characteristics such as seed test and panicle density. The three low-seed-yield populations differed mainly for plant height, $\mathrm{HI}$, and seeds per panicle.

Due to the difficulty to group genotypes using only the PCA analysis, cluster analysis was performed to reveal any connections among these germplasm accessions. Similar populations were clustered according to minimal distance analysis on the basis of the mean values of the six principal components. The 109 genotypes examined can be agglomerated into nine clusters at a Euclidian distance of $22 \%$ (Figure 2). Cluster analysis, according to the results obtained 
TABLE 1: Monthly maximum and minimum temperatures, total rainfall, and growing degree days (GDD) accumulation at Foggia during 2008-2009 and 2009-2010 growing seasons with the long-term (52-year) average.

\begin{tabular}{|c|c|c|c|c|c|c|c|c|c|c|c|}
\hline & \multicolumn{3}{|c|}{ Maximum temperature } & \multicolumn{3}{|c|}{ Minimum temperature } & \multicolumn{3}{|c|}{ Rainfall } & \multicolumn{2}{|c|}{ GDD } \\
\hline & 2008-09 & 2009-10 & 52-year average & $\begin{array}{l}2008-09 \\
\mathrm{C}\end{array}$ & $2009-10$ & 52-year average & 2008-09 & $\begin{array}{r}2009-10 \\
\mathrm{~mm}\end{array}$ & 52-year average & 2008-09 & $\begin{array}{l}2009-10 \\
d\end{array}$ \\
\hline November & 16.2 & 16.5 & 17.1 & 7.1 & 6.9 & 7.3 & 63.0 & 46.8 & 59.4 & 348.4 & 342.4 \\
\hline December & 11.8 & 12.5 & 13.2 & 4.2 & 4.7 & 4.4 & 86.3 & 73.0 & 62.9 & 242.1 & 267.8 \\
\hline January & 10.0 & 9.9 & 11.7 & 3.1 & 2.8 & 2.9 & 82.6 & 69.8 & 49.8 & 219.5 & 195.7 \\
\hline February & 11.6 & 12.1 & 13.0 & 2.9 & 3.6 & 3.0 & 64.8 & 75.3 & 42.3 & 166.7 & 214.4 \\
\hline March & 14.3 & 14.8 & 15.8 & 3.9 & 3.7 & 4.4 & 54.3 & 48.3 & 45.0 & 282.3 & 290.2 \\
\hline April & 18.4 & 17.9 & 19.4 & 7.4 & 6.7 & 6.6 & 68.5 & 52.3 & 46.7 & 402.0 & 368.6 \\
\hline May & 24.4 & 23.8 & 25.2 & 11.8 & 11.3 & 10.9 & 46.8 & 41.3 & 36.9 & 594.8 & 535.9 \\
\hline June & 28.4 & 28.2 & 30.0 & 15.1 & 14.6 & 14.9 & 45.2 & 39.3 & 42.3 & 651.5 & 641.6 \\
\hline Mean & 16.9 & 17.0 & 18.2 & 6.9 & 6.8 & 6.8 & & & & & \\
\hline Sum & & & & & & & 511.5 & 445.8 & 385.3 & 2907.3 & 2856.5 \\
\hline
\end{tabular}

TABle 2: Descriptive statistics for the 13 characters of the 109 oat genotypes.

\begin{tabular}{lccc}
\hline Character $^{\dagger}$ & Mean \pm SE & Range & CV (\%) \\
\hline HT (days from 1 April) & $38.3 \pm 0.5$ & $18.0-45.0^{*}$ & 13.3 \\
MT (days from 1 April) & $79.6 \pm 0.5$ & $67.0-87.0^{*}$ & 6.7 \\
FP (days) & $0.3 \pm 0.9$ & $18.0-64.0^{* *}$ & 24.2 \\
FOS (\% d.w.) & $2.40 \pm 0.09$ & $1.12-6.70$ & 36.5 \\
PH $(\mathrm{cm})$ & $133.0 \pm 1.0$ & $107.5-162.5^{* *}$ & 7.7 \\
SY $\left(\mathrm{g} \mathrm{m}^{-2}\right)$ & $304.0 \pm 10.8$ & $118.0-606.0^{* *}$ & 37.1 \\
HI $(\%)$ & $22.4 \pm 0.7$ & $5.1-42.6$ & 31.2 \\
ST $\left(\mathrm{kg} \mathrm{hL}^{-1}\right)$ & $42.4 \pm 0.4$ & $33.9-53.5^{* *}$ & 9.1 \\
NP/m $/ \mathrm{m}^{2}\left(\right.$ no. $\left.\mathrm{m}^{-2}\right)$ & $52.0 \pm 0.9$ & $36.0-84.0$ & 17.3 \\
$\mathrm{NPa} / \mathrm{m}^{2}\left(\right.$ no. $\left.\mathrm{m}^{-2}\right)$ & $494.9 \pm 13.2$ & $246.0-918.0$ & 27.8 \\
$\mathrm{SW} / \mathrm{Pa}(\mathrm{g})$ & $1.46 \pm 0.05$ & $0.26-2.99$ & 32.8 \\
$\mathrm{NS} / \mathrm{Pa}($ no. $)$ & $64.9 \pm 2.0$ & $19.7-133.8$ & 32.2 \\
$\mathrm{TSW}$ (g) & $25.0 \pm 0.4$ & $13.7-36.5^{* *}$ & 18.3 \\
\hline
\end{tabular}

${ }^{\dagger}$ HT: days to heading, MT: Days to maturity, FP: filling period, FOS: FOS content, PH: plant height, SY: seed yield, HI: harvest index, ST: seed test, $\mathrm{NP} / \mathrm{m}^{2}$ : number of plants per $\mathrm{m}^{2}, \mathrm{NPa} / \mathrm{m}^{2}$ : number of panicles per $\mathrm{m}^{2}$, SW/Pa: seed weight per panicle, NS/Pa: number of seeds per panicle, TSW: thousand seed weight.

$*, * *$ Denotes that variance among genotypes is statistically significant at $5 \%$ and $1 \%$ level of probability, respectively.

from PCA, revealed extreme variations among the genotypes. The highest and lowest values of the original traits for each cluster are also listed in Figure 2. The clusters contained from 5 to 22 accessions that were similar for specific traits. In particular, clusters I to IX involved 22 (with higher maturity time, taller plants, and high FOS content), 14 (with high seed test and lower mean values for seed yield, HI and TSW), 12 (with longer FP and early heading time), 15 (with higher $\mathrm{NP} / \mathrm{m}^{2}$ ), 6 (with higher $\mathrm{HI}$ and $\mathrm{NPa} / \mathrm{m}^{2}$ ), 17 (with higher $\mathrm{SW} / \mathrm{Pa}$ and NS/Pa), 8 (with higher seed yield, HI and TSW), 10 (with lower $\mathrm{NP} / \mathrm{m}^{2}, \mathrm{NPa} / \mathrm{m}^{2}$ and $\mathrm{NS} / \mathrm{Pa}$ ), and 5 (with late heading time) populations, respectively. In particular, clusters III and VII were consistent with the results of the first two PCs, as they included the earliest and the most productive accessions, respectively.

\section{Discussion}

According to Richards [15] and Shorter et al. [16], the first step towards maximising crop yields by agronomy or plant breeding is to ensure that the crop phenology is well fitted to the available resources of the production environment. In the present study, the analysis of bioagronomic traits shows pronounced variation among these 109 oat populations that can be useful for a variety of improvement programmes. The data show that the genotypes evaluated were mainly heterogeneous for seed yield and FOS content. A large variation in FOS concentration was also reported by Livingston et al. [17] in more than 200 lines of oat evaluated at the tillering stage of plant development. Genetic variability for FOS concentration was high enough to allow more detailed physiological studies with fewer accessions that have a wide range of FOS content.

The heading time is an important characteristic for determination of the final seed production in the Mediterranean environments where high temperatures in spring are frequent. Usually, the heading time in oat under the southern Italy climate conditions occurs in the first ten days of May. Indeed, early flowering allows a long seedfill period, during which the leaves remain green and the seed fill is improved. Therefore, high yields in oat might be related to rapid seed filling characteristics, and so the adaptation to the environment might be improved through selection of early flowering genotypes [18]. The importance of the earliness trait, as the mechanism of response to abiotic stress in the final phase of the biological cycle, has been confirmed by the significant negative correlation found between heading time and seed yield. The higher range and variation measured for heading time, in comparison with maturity time, indicate that there is good potential for improving these oat accessions for this trait.

Furthermore, according to Redaelli et al. [18], high seed yield in oat is negatively correlated with plant height and positively correlated with seed weight. The plant height is very important in terms of resistance to lodging and HI. A gradual reduction in the plant height associated with 
TABLE 3: Correlation coefficients between the 13 characters of the 109 oat genotypes.

\begin{tabular}{|c|c|c|c|c|c|c|c|c|c|c|c|c|}
\hline Character $^{\dagger}$ & 1 & 2 & 3 & 4 & 5 & 6 & 7 & 8 & 9 & 10 & 11 & 12 \\
\hline (1) HT (days from 1 April) & - & & & & & & & & & & & \\
\hline (2) MT (days from 1 April) & 0.06 & & & & & & & & & & & \\
\hline (3) FP (days) & $-0.84^{* *}$ & $0.49^{* *}$ & & & & & & & & & & \\
\hline (4) FOS (\% d.w.) & -0.02 & -0.05 & -0.01 & & & & & & & & & \\
\hline (5) $\mathrm{PH}(\mathrm{cm})$ & 0.13 & $0.19^{*}$ & -0.01 & 0.12 & & & & & & & & \\
\hline (6) $\mathrm{SY}\left(\mathrm{g} \mathrm{m}^{-2}\right)$ & $-0.30 * *$ & $-0.57^{* *}$ & -0.05 & -0.10 & $-0.27^{* *}$ & & & & & & & \\
\hline (7) $\mathrm{HI}(\%)$ & $-0.21^{*}$ & $-0.29 * *$ & 0.02 & -0.11 & $-0.26^{* *}$ & $0.61^{* *}$ & & & & & & \\
\hline (8) ST $\left(\mathrm{kg} \mathrm{hL}^{-1}\right)$ & -0.01 & -0.01 & 0.01 & -0.03 & $0.22^{*}$ & -0.05 & -0.19 & & & & & \\
\hline (9) $\mathrm{NP} / \mathrm{m}^{2}\left(\right.$ no. $\left.\mathrm{m}^{-2}\right)$ & 0.07 & $0.41^{* *}$ & 0.17 & 0.05 & -0.01 & -0.17 & $-0.22^{*}$ & -0.06 & & & & \\
\hline (10) $\mathrm{NPa} / \mathrm{m}^{2}\left(\right.$ no. $\mathrm{m}^{-2}$ ) & -0.11 & $0.37^{* *}$ & $0.30^{* *}$ & -0.09 & -0.13 & 0.04 & $0.25^{* *}$ & 0.10 & $0.32^{* *}$ & & & \\
\hline (11) $\mathrm{SW} / \mathrm{Pa}(\mathrm{g})$ & -0.08 & -0.07 & 0.04 & -0.04 & -0.12 & $0.33^{* *}$ & $0.54^{* *}$ & -0.16 & 0.01 & 0.05 & & \\
\hline (12) NS/Pa (no.) & 0.09 & 0.02 & -0.07 & -0.03 & -0.15 & 0.12 & $0.24^{*}$ & -0.17 & 0.12 & -0.05 & $0.84^{* *}$ & \\
\hline (13) TSW (g) & $-0.34^{* *}$ & $-0.23^{*}$ & 0.17 & 0.10 & 0.02 & $0.38^{* *}$ & $0.48^{* *}$ & $-0.20^{*}$ & -0.14 & 0.12 & $0.32 * *$ & -0.03 \\
\hline
\end{tabular}

${ }^{\dagger}$ HT: days to heading, MT: days to maturity, FP: filling period, FOS: FOS content, PH: plant height, SY: seed yield, HI: harvest index, ST: seed test, NP/m ${ }^{2}$ : number of plants per $\mathrm{m}^{2}, \mathrm{NPa} / \mathrm{m}^{2}$ : number of panicles per $\mathrm{m}^{2}$, SW/Pa: seed weight per panicle, NS/Pa: number of seeds per panicle, TSW: thousand seed weight.

*,** significant at $P \leq 0.05$ and $P \leq 0.01$.

TABLE 4: PCA of the 13 characters associated with the 109 oat genotypes, showing the eigenvalues and the proportions of variation associated with the first six axes and eigenvectors of characters.

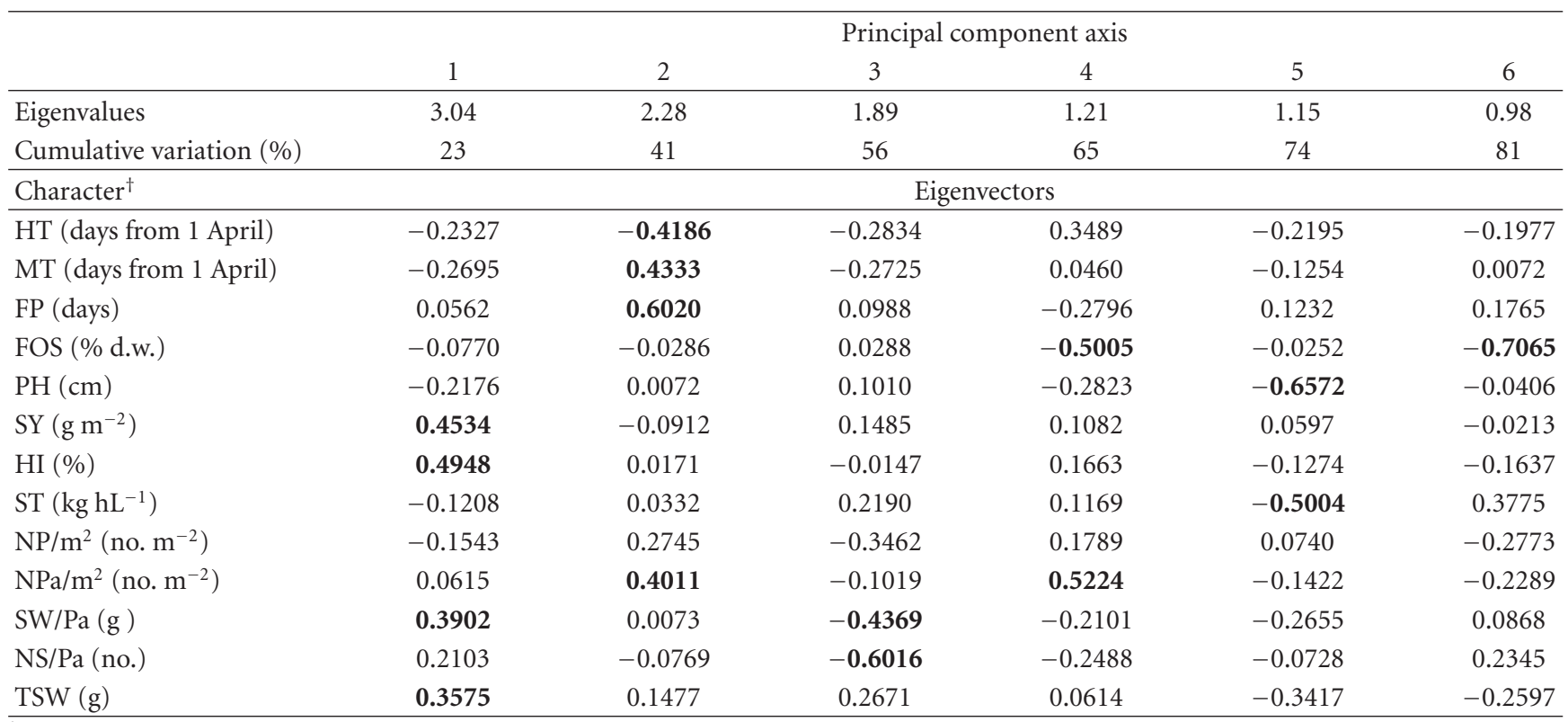

${ }^{\dagger}$ HT: days to heading, MT: days to maturity, FP: filling period, FOS: FOS content, PH: plant height, SY: seed yield, HI: harvest index, ST: Seed test, NP/m ${ }^{2}$ : number of plants per $\mathrm{m}^{2}, \mathrm{NPa} / \mathrm{m}^{2}$ : number of panicles per $\mathrm{m}^{2}$, SW/Pa: seed weight per panicle, NS/Pa: number of seeds per panicle, TSW: thousand seed weight.

an increased HI has represented the main breeding goal in cereals, with an effect on the sink capacity and the biomass partitioning [19]. Moreover, in the present study, seed yield was positively correlated with seed weight per panicle, a trait that was considered by Peltonen-Sainio [20] to be a more suitable parameter to define the productive oat ideotype.

According to Peterson et al. [4], knowledge of some of the relationships among different traits can help breeders to optimise some traits simultaneously. As the correlation analysis can only show the association between single traits, multivariate analysis has been used to quantify similarities and dissimilarities as well as to assess relative contributions of various traits to the total variability in germplasm collections [12, 14, 21, 22]. Furthermore, classification using multiple agronomic characteristics helps to more precisely identify a cultivar's adaptation and would improve the evaluation of a cultivar for potential adaptation [23]. Our data show that each trait is an important source of variation in at least one principal component axis although there was not a single trait in a principal component that could explain a reasonable extent of variation. However, considering the loading relative to $\mathrm{PC} 1$ and $\mathrm{PC} 2$, it can be inferred that 
TABLE 5: Most divergent populations according to variation along with the first and the second principal components.

\begin{tabular}{|c|c|c|c|c|c|c|}
\hline \multirow{2}{*}{ Character $^{\dagger}$} & \multicolumn{3}{|c|}{ High seed yield population } & \multicolumn{3}{|c|}{ Low seed yield population } \\
\hline & CW 0002/58 & Fulvia & Genziana & Mosty $\times 885.263$ & Rhea $\times$ Peniarth & Terra \\
\hline HT (days from 1 April) & 18 & 34 & 30 & 45 & 45 & 44 \\
\hline MT (days from 1 April) & 78 & 78 & 78 & 84 & 84 & 84 \\
\hline FP (days) & 60 & 44 & 48 & 39 & 39 & 40 \\
\hline FOS (\% d.w.) & 5.2 & 2.4 & 1.3 & 2.1 & 3.3 & 1.7 \\
\hline $\mathrm{PH}(\mathrm{cm})$ & 120 & 130 & 130 & 140 & 150 & 140 \\
\hline $\mathrm{SY}\left(\mathrm{g} \mathrm{m}^{-2}\right)$ & 520 & 470 & 554 & 150 & 244 & 184 \\
\hline $\mathrm{HI}(\%)$ & 29 & 38 & 43 & 13 & 8 & 5 \\
\hline $\mathrm{ST}\left(\mathrm{kg} \mathrm{hL}^{-1}\right)$ & 38 & 41 & 46 & 48 & 52 & 50 \\
\hline $\mathrm{NP} / \mathrm{m}^{2}\left(\right.$ no. $\left.\mathrm{m}^{-2}\right)$ & 54 & 54 & 48 & 60 & 60 & 60 \\
\hline $\mathrm{NPa} / \mathrm{m}^{2}\left(\right.$ no. $\left.\mathrm{m}^{-2}\right)$ & 540 & 882 & 768 & 456 & 438 & 570 \\
\hline $\mathrm{SW} / \mathrm{Pa}(\mathrm{g})$ & 2.0 & 2.0 & 3.0 & 1.0 & 0.3 & 0.4 \\
\hline $\mathrm{NS} / \mathrm{Pa}$ (no.) & 91 & 75 & 100 & 81 & 20 & 22 \\
\hline TSW (g) & 31 & 28 & 31 & 14 & 14 & 15 \\
\hline
\end{tabular}

${ }^{\dagger}$ HT: days to heading, MT: days to maturity, FP: filling period, FOS: FOS content, PH: plant height, SY: seed yield, HI: harvest index, ST: seed test, NP/m ${ }^{2}$ : number of plants per $\mathrm{m}^{2}, \mathrm{NPa} / \mathrm{m}^{2}$ : number of panicles per $\mathrm{m}^{2}$, SW/Pa: seed weight per panicle, NS/Pa: number of seeds per panicle, TSW: thousand seed weight.

the yield characteristics together with phenology are the major sources of diversity.

As reported by Firincioğlu et al. [24], biplot diagrams can be used to select genotypes that might have favourable combinations of traits for use in a breeding project. For example, if an objective was to increase seed yield, genotypes that fall in the right quadrants are generally above average for this specific trait. In the present study, the ordination of the accessions along the axes of the first and second principal components revealed two distinct clusters, on the basis of heading time and seed yield. However, different genotypes can be considered as potential sources of earliness, although they are not suitable for improvements to seed yield.

Indeed, these data have revealed different associations between traits in the materials studied. This suggests that through selection, there is the possibility of obtaining suitable genotypes that can combine high yield with desirable traits, to use these in future selection programmes. As populations with the same potential productivity appeared to be considerably different for the other traits, their high performances in SY can be a consequence of different gene pools. If this is true, by crossing these, very wide genetic variation can be achieved in the segregating generations [25]. This gives us the opportunity of synthesising oat varieties that are characterised by different heading times, plant heights and/or FOS contents.

Among the most productive genotypes, Genziana and CW 0002/58 showed high and low HI values, respectively. According to Peltonen-Sainio et al. [26], this confirms the complex nature of $\mathrm{HI}$ and its dependence on its components (vegetative biomass and grains). Furthermore, PeltonenSainio et al. [26] found that for oat, grain yield had high, contrasting loadings to phytomass. In our case, it appears that in CW 0002/58 the increased grain yield was not obtained at the expense of vegetative above-ground biomass. In other words, it appears that Genziana and CW 0002/58 represent the good ideotypes for grain and forage biomass yields in the Mediterranean environment.

The cluster analysis calculated according to the first six principal components shows remarkable inter-group and intragroup diversity. The dendogram obtained consists of nine groups and a number of subgroups that result from different morphological and agronomic traits. It has been hypothesised that these groups would predict genetic similarities among cultivars [23]. The multivariate approach appears, therefore, to be a valid system for germplasm evaluation in oat, which allows the detailed characterisation of populations in terms of their adaptation and productivity, with higher discriminatory capacity in comparison to separate single trait analysis. From a breeding point of view, according to Veronesi and Falcinelli [25], the presence of remarkable diversity within the germplasm collection appears to be of great interest in providing valuable materials for breeding programmes that are aimed at oat improvement in the environment studied, which is representative of the Mediterranean climate.

\section{Conclusions}

The analysis of variation of these 109 accessions has provided interesting information about the associations of characters that are useful for the formulation of better hypotheses for breeding studies. Indeed, the absence of strong associations among the investigated traits allows useful recombinants to be obtained for breeding studies. Furthermore, this analysis clearly shows the independent variation of FOS content, which suggests that in a broadly based breeding programme, it should be possible to independently manipulate the quality traits of the forage and grain. Improvements in grain yield in oat cultivars should result from genetic changes in the ability to yield grain at the expense of vegetative, above-ground biomass (high $\mathrm{HI}$ ) and to obtain good kernel weight and test weight. Genotypes of clusters V, VI, and VII show these 


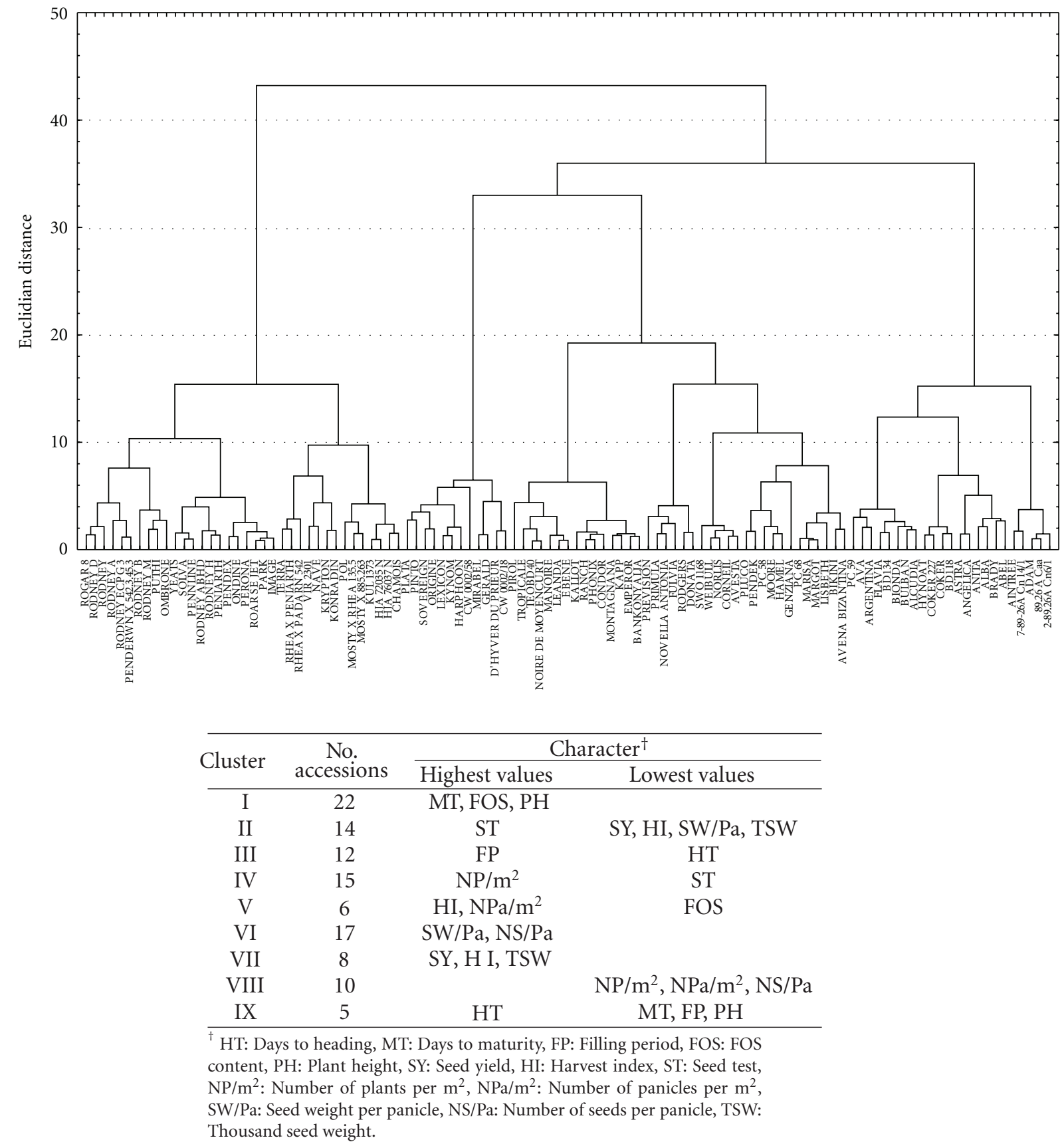

FIGURE 2: Dendrogram generated by Ward's method of cluster analysis that accounts for $81 \%$ of the phenotipic variation among the 109 oat accessions, and number and characteristics of the accessions within each cluster.

desirable characteristics. A fodder-yielding plant should be tall and leafy, with a longer vegetative phase and a greater biomass (low HI). Genotypes of clusters I, II, and IX have most of these characteristics, along with high biomass FOS content, which makes them suitable as green fodder crops.

The present study has, therefore, contributed to our increasing knowledge of the available oat germplasm, and on the basis of the definition of ideotypes, it emphasises the potential for developing varieties for different purposes, such as for food or forage. However, further studies should be carried out to confirm these data.

\section{References}

[1] J. M. Suttie and S. G. Reynolds, Fodder Oats: A World Overview. FAO, 2004, http://www.fao.org/docrep/008/y5765e/ y5765e00.htm.

[2] A. Corleto, "Gli erbai in Italia meridionale," L'Italia Agricola, vol. 2, pp. 99-109, 1987. 
[3] Food and Drug Administration, "Food labeling: health claims; oats and coronary heart disease; final rule," Federal Register, vol. 62, pp. 3583-3601, 1997.

[4] D. M. Peterson, D. M. Wesenberg, D. E. Burrup, and C. A. Erickson, "Relationships among agronomic traits and grain composition in oat genotypes grown in different environments," Crop Science, vol. 45, no. 4, pp. 1249-1255, 2005.

[5] R. Redaelli, D. Sgrulletta, and E. De Stefanis, "Genetic variability for chemical components in sixty European oat (Avena sativa L.) cultivars," Cereal Research Communications, vol. 31, no. 1-2, pp. 185-192, 2003.

[6] R. Saksena, D. Deepak, A. Khare, R. Sahai, L. M. Tripathi, and V. M. L. Srivas, "A novel pentasaccharide from immunostimmulant oligosaccharide fraction of buffalo milk," Biochimica et Biophysica Acta, vol. 1428, pp. 433-445, 1999.

[7] E. Leiva, M. B. Hall, and H. H. Van Horn, "Performance of dairy cattle fed citrus pulp or corn products as sources of neutral detergent-soluble carbohydrates," Journal of Dairy Science, vol. 83, no. 12, pp. 2866-2875, 2000.

[8] M. F. Martinez, H. M. Arelovich, and L. N. Wehrhahne, "Grain yield, nutrient content and lipid profile of oat genotypes grown in a semiarid environment," Field Crops Research, vol. 116, no. 1-2, pp. 92-100, 2010.

[9] E. J. Stevens, K. W. Armstrong, H. J. Bezar, W. B. Griffin, and J. B. Hampton, "Fodder oats: an overview," in Fodder Oats: A World Overview, J. M. Suttie and S. G. Reynolds, Eds., Plant Production and Protection Series, No. 33, pp. 11-18, FAO, Rome, Italy, 2004.

[10] N. V. Greene, K. E. Kenworthy, K. H. Quesenberry, J. B. Unruh, and J. B. Sartain, "Diversity and relatedness of common carpetgrass germplasm," Crop Science, vol. 48, no. 6, pp. 22982304, 2008.

[11] A. Achleitner, N. A. Tinker, E. Zechner, and H. Buerstmayr, "Genetic diversity among oat varieties of worldwide origin and associations of AFLP markers with quantitative traits," Theoretical and Applied Genetics, vol. 117, no. 7, pp. 10411053, 2008.

[12] A. Rezai and K. J. Frey, "Multivariate analysis of variation among wild oat accessions - seed traits," Euphytica, vol. 49, no. 2, pp. 111-119, 1990.

[13] P. H. A. Sneath and R. R. Sokal, Numerical Taxonomy: The Principle and Practice of Numerical Classification, W.H. Freeman, San Francisco, Calif, USA, 1973.

[14] F. Flores, J. C. Gutierrez, J. Lopez, M. T. Moreno, and J. I. Cubero, "Multivariate analysis approach to evaluate a germplasm collection of Hedysarum coronarium L," Genetic Resources and Crop Evolution, vol. 44, no. 6, pp. 545-555, 1997.

[15] R. A. Richards, "Breeding for drought resistance physiological approaches," in Drought Resistance in Cereals, F. W. G. Baker, Ed., p. 65, CAB International, Wallingford, UK, 1989.

[16] R. Shorter, R. J. Lawn, and G. L. Hammer, "Improving genotypic adaptation in crops-a role for breeders, physiologists and modellers," Experimental Agriculture, vol. 27, no. 2, pp. 155-175, 1991.

[17] D. P. Livingston III, G. F. Elwinger, and J. C. Weaver, "Fructan and sugars in 273 oat accessions," Crop Science, vol. 33, pp. 525-529, 1993.

[18] R. Redaelli, P. Laganà, F. Rizza, O. Li Destri Nicosia, and L. Cattivelli, "Genetic progress of oats in Italy," Euphytica, vol. 164, no. 3, pp. 679-687, 2008.

[19] P. De Vita, O. Li Destri Nicosia, F. Nigro et al., "Breeding progress in morpho-physiological, agronomical and qualitative traits of durum wheat cultivars released in Italy during the 20th century," European Journal of Agronomy, vol. 26, no. 1, pp. 39-53, 2007.

[20] P. Peltonen-Sainio, "Productive oat ideotype for northern growing conditions," Euphytica, vol. 54, no. 1, pp. 27-32, 1991.

[21] M. Pezzotti, C. Tomassini, M. Falcinelli, and F. Veronesi, "Evaluation of an Italian germplasm collection of Dactylis glomerata L. using a multivariate approach," Journal of Genetics and Breeding, vol. 48, no. 1, pp. 17-24, 1994.

[22] D. R. Panthee, R. B. Kc, H. N. Regmi, P. P. Subedi, S. Bhattarai, and J. Dhakal, "Diversity analysis of garlic (Allium sativum L.) germplasms available in Nepal based on morphological characters," Genetic Resources and Crop Evolution, vol. 53, no. 1, pp. 205-212, 2006.

[23] E. Souza and M. E. Sorrells, "Relationships among 70 North American oat germplasms: I. Cluster analysis using quantitative characters," Crop Science, vol. 31, pp. 599-605, 1991.

[24] H. K. Firincioğlu, E. Erbektaş, L. Doğruyol, Z. Mutlu, S. Ünal, and E. Karakurt, "Phenotypic variation of autumn and springsown vetch (Vicia sativa ssp.) populations in central Turkey," Spanish Journal of Agricultural Research, vol. 7, no. 3, pp. 596606, 2009.

[25] F. Veronesi and M. Falcinelli, "Evaluation of an Italian germplasm collection of Festuca arundinacea Schreb. through a multivariate analysis," Euphytica, vol. 38, no. 3, pp. 211-220, 1988.

[26] P. Peltonen-Sainio, S. Muurinen, A. Rajala, and L. Jauhiainen, "Variation in harvest index of modern spring barley, oat and wheat cultivars adapted to northern growing conditions," Journal of Agricultural Science, vol. 146, no. 1, pp. 35-47, 2008. 


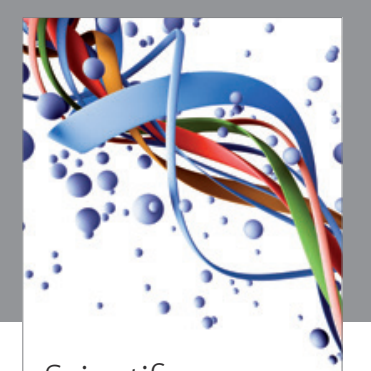

Scientifica
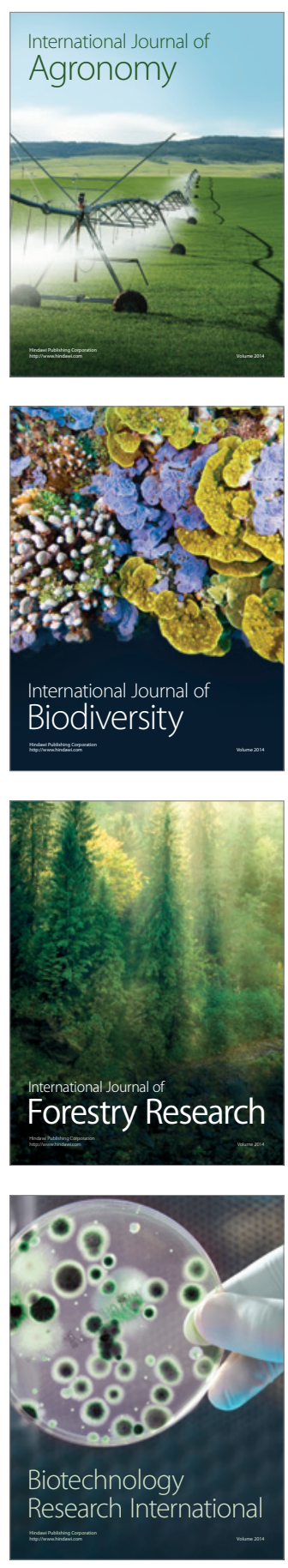
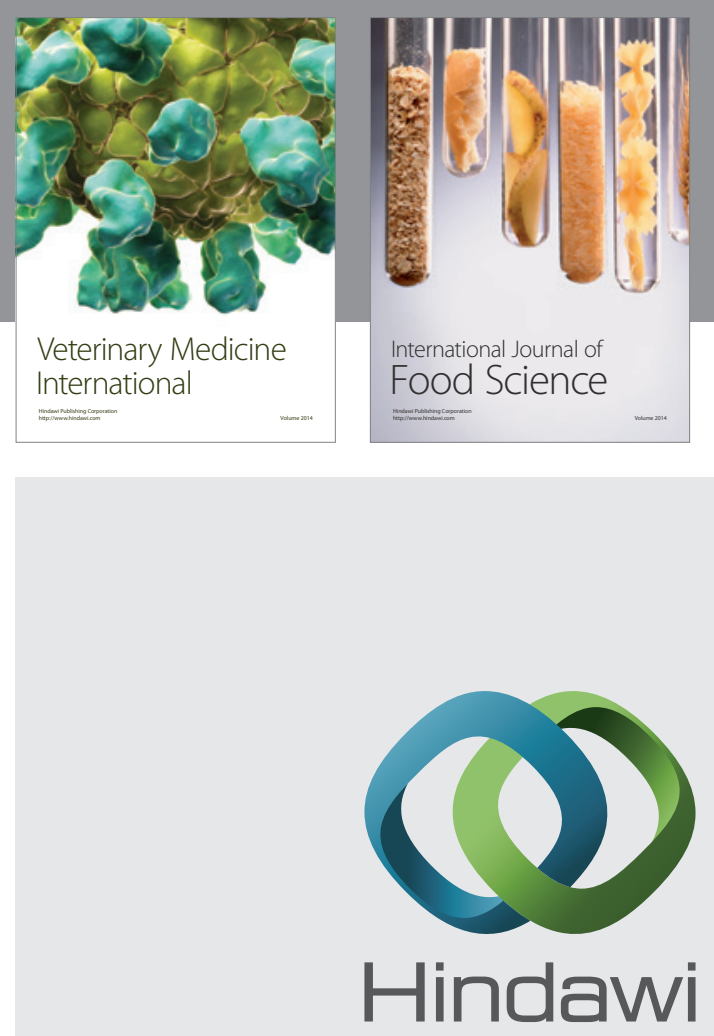

Submit your manuscripts at

http://www.hindawi.com
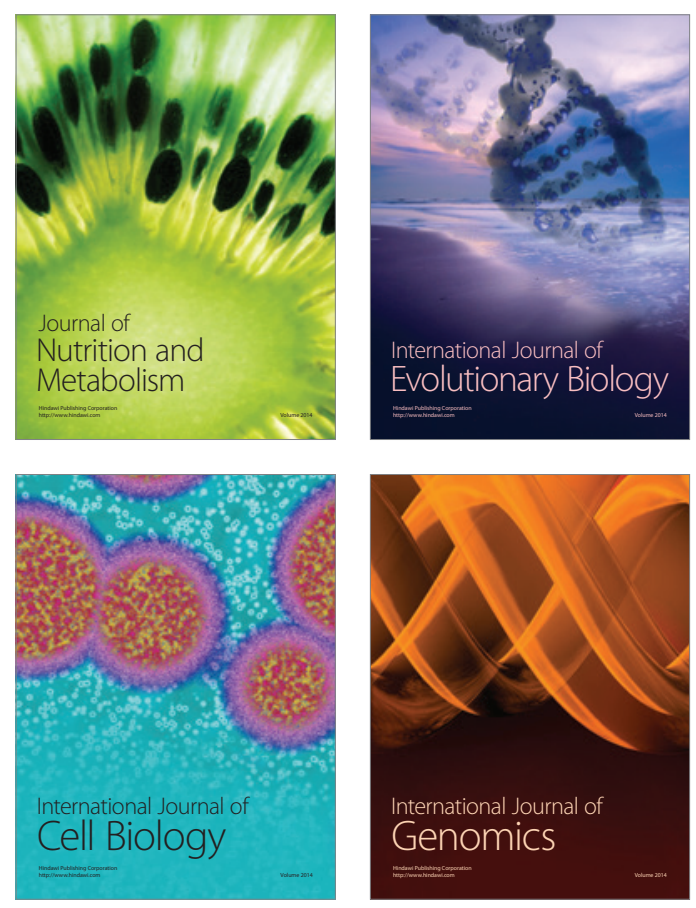
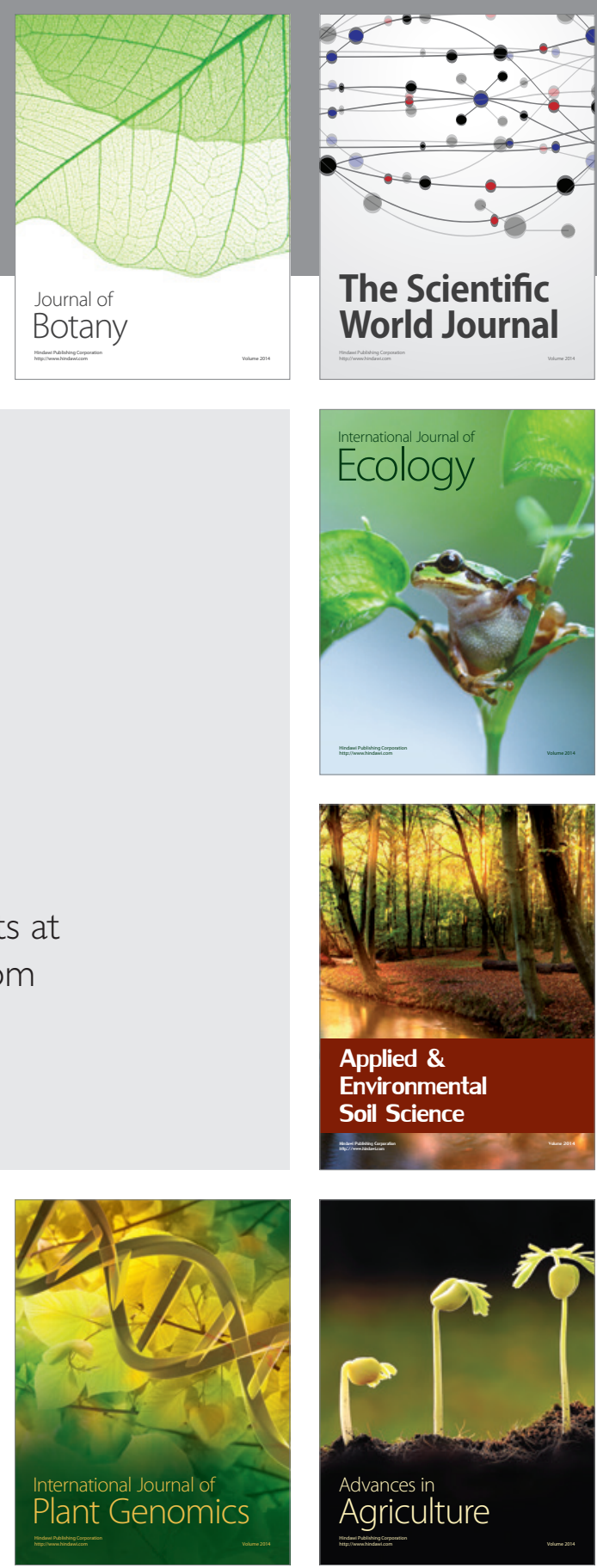

The Scientific World Journal
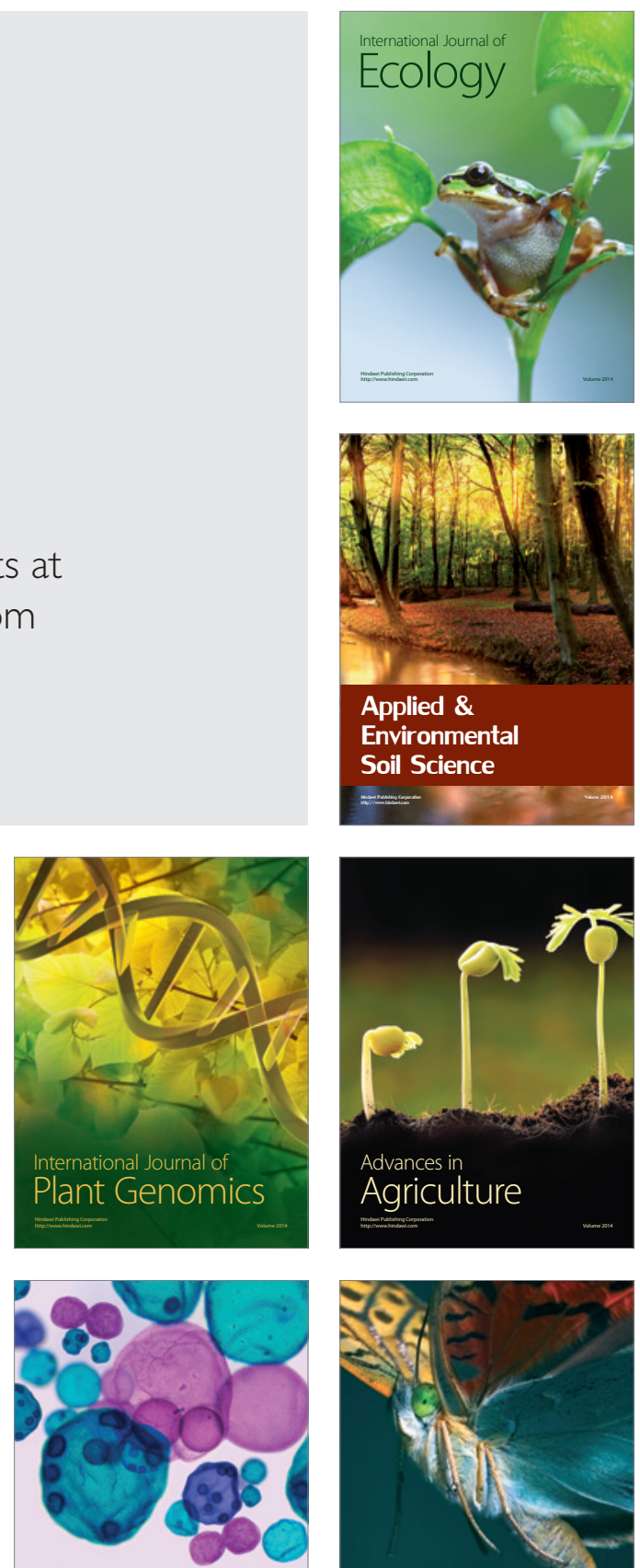

International Journal of Microbiology

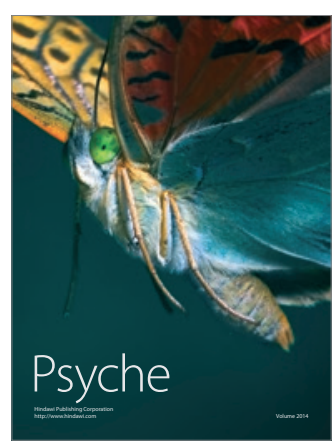

